Research Article

\title{
Genetic parameters for body weight, carcass chemical composition and yield in a broiler-layer cross developed for QTL mapping
}

\author{
Beatriz do Nascimento Nunes ${ }^{1}$, Salvador Boccaletti Ramos ${ }^{1}$, Rodrigo Pelicioni Savegnago ${ }^{1}$, \\ Mônica Corrêa Ledur ${ }^{2}$, Kátia Nones ${ }^{3}$, Claudete Hara Klein ${ }^{1}$ and Danísio Prado Munari ${ }^{1}$ \\ ${ }^{1}$ Departamento de Ciências Exatas, Faculdade de Ciências Agrárias e Veterinárias, \\ Universidade Estadual Paulista "Júlio de Mesquita Filho", Jaboticabal, SP, Brazil. \\ ${ }^{2}$ Empresa Brasileira de Pesquisa Agropecuária Suínos e Aves, Concórdia, SC, Brazil. \\ ${ }^{3}$ Laboratório de Biotecnologia Animal, Escola Superior de Agricultura "Luiz de Queiroz, \\ Universidade de São Paulo, Piracicaba, SP, Brazil.
}

\begin{abstract}
The objective of this study was to estimate genetic and phenotypic correlations of body weight at 6 weeks of age (BW6), as well as final carcass yield, and moisture, protein, fat and ash contents, using data from 3,422 F2 chickens originated from reciprocal cross between a broiler and a layer line. Variance components were estimated by the REML method, using animal models for evaluating random additive genetic and fixed contemporary group (sex, hatch and genetic group) effects. The heritability estimates $\left(\mathrm{h}^{2}\right)$ for BW6, carcass yield and percentage of carcass moisture were $0.31 \pm 0.07,0.20 \pm 0.05$ and $0.33 \pm 0.07$, respectively. The $h^{2}$ for the percentages of protein, fat and ash on a dry matter basis were $0.48 \pm 0.09,0.55 \pm 0.10$ and $0.36 \pm 0.08$, respectively. BW6 had a positive genetic correlation with fat percentage in the carcass, but a negative one with protein and ash contents. Carcass yield, thus, appears to have only low genetic association with carcass composition traits. The genetic correlations observed between traits, measured on a dry matter basis, indicated that selection for carcass protein content may favor higher ash content and a lower percentage of carcass fat.
\end{abstract}

Key words: broiler, carcass composition, genetic correlation.

Received: April 27, 2010; Accepted: February 21, 2011.

\section{Introduction}

Great progress has been made in broiler production over the past few decades, and about 85 to $90 \%$ of the increase in productivity is attributed to genetics (Chambers, 1995). Broilers are mainly selected by certain performance traits, such as body-weight at marketing age. However, intense selection for rapid growth has been accompanied by negative consequences, including skeletal problems and increased carcass fat deposition (Burt, 2002). Even though difficult and costly (Ikeobi et al., 2002; Lagarrigue et al., 2006), phenotype-based selection methods for reducing fat deposition have improved carcass composition by reducing overall fatness. Though this has been in detriment of meatquality (Nadaf et al., 2007).

The identification of markers and genes that control phenotypic variation in quantitative traits remains a major challenge. Quantitative trait locus (QTL) mapping is a

Send correspondence to Danísio Prado Munari. Departamento de Ciências Exatas, Faculdade de Ciências Agrárias e Veterinárias, Universidade Estadual Paulista "Júlio de Mesquita Filho", Via de Acesso Prof.Paulo Donato Castellane s/n, 14884-900 Jaboticabal, SP, Brazil. E-mail: danisio@ fcav.unesp.br. method that has been used successfully to examine genetic contributions to certain quantitative traits, by correlating allelic variation in polymorphic genetic markers with trait variability (Tercic et al., 2009). The identification of markers linked to genomic regions that regulate economically important traits could be useful in marker assisted selection. QTL mapping is the first stage in identifying chromosomal regions involved in the genetic control of traits that are economically important for the chicken industry. The genetic correlations between traits can provide information on how much genetic overlap exists between traits, and support QTL findings (Nones et al., 2005).

The favorable progress in chicken performance is associated with an increase in fat deposition, possibly due to positive genetic correlations between body-weight and fat production traits (Zerehdaran et al., 2004). According to Leenstra et al. (1986), the application of body weight as a selection criterion has favored chickens with larger appetites. These eat more than required for muscle development, growth and maintenance, whereby this excessive energy is accumulated in the form of fat (Lin, 1981; Leenstra et al., 1986; Havenstein et al., 1988). 
Carcass chemical composition traits, such as protein, fat and ash, are of great economic importance for the poultry segment, because they are directly related to the efficiency in meat production. Nevertheless, the evaluation of carcass chemical composition remains both difficult and costly. Genetic parameter estimates for these traits have been rarely reported, mostly due to the need for evaluating a large number of animals, so as to obtain reliable var-covariance component estimates. In this study we estimated genetic parameters for protein, fat, ash, and moisture in the carcass, as well as body-weight and carcass yield, in an F2 population designed to map quantitative trait loci (QTL) on a population of more than 3,000 chickens. This information, essential for a better understanding of the genetic architecture of carcass chemical composition in chickens, could possibly contribute to the development of new selection strategies in future broiler-breeding programs.

\section{Materials and Methods}

\section{Experimental population}

Two F2-chicken-resource populations (TCTC and CTCT) were developed at the Embrapa Swine and Poultry National Research Center, Brazil, by reciprocally crossing a broiler (TT) and layer (CC) lines, so as to produce populations with segregating QTL for performance and carcass traits. TT is a broiler male-line, with a genetic background of Cornish, Hampshire and White Plymouth Rock breeds, selected to improve body-weight, feed conversion, retailcut yield, breast-weight, viability, fertility, hatchability, and reduced abdominal fat. CC is a pure White Leghorn line selected for egg production, egg-weight, feed conversion, hatchability, sexual maturity, fertility, viability, egg quality, and reduced body weight. When the F2 population was developed, the TT and CC lines involved had already undergone multi-trait selection for six and eight generations, respectively.

Seven TT males were mated to seven CC females to generate seven F1 TC families, totalizing about 50 chickens, and seven CC males were mated to seven TT females, giving rise to seven $\mathrm{F} 1 \mathrm{CT}$ families of about 50 chickens, as well. Seven TC males and 21 TC females, and seven CT males and $21 \mathrm{CT}$ females (in both cases one male and three females from each full-sib family), were chosen at random to be parents of the F2 population. The F1 chickens chosen to generate the F2 population were reared as broiler-breeders. Each F1 male was mated to three non-related F1 females by artificial insemination to avoid inbreeding. Each F1 female produced around 100 F2 offspring in 17 hatches over eight months in 1999 and 2000, resulting in around 4,000 F2 individuals (half of each sex and each mating CTCT and TCTC). Carcass-related traits were recorded for 3,422 (1,673 females and 1,749 males).

The F2 chickens, reared as broilers, received food and water ad libitum. A commercial broiler diet containing a metabolizable energy concentration (ME) of $3,150 \mathrm{kcal} / \mathrm{kg}$ and $21 \%$ crude protein (1 to 21 days), 3,200 $\mathrm{kcal} \mathrm{ME} / \mathrm{kg}$ and $20 \%$ crude protein (22 to 35 days), and $3,200 \mathrm{kcal}$ $\mathrm{ME} / \mathrm{kg}$ and $18.5 \%$ crude protein (36 to 41 days) was provided.

\section{Description of traits}

The body-weight of live chickens was recorded at 6 weeks of age (BW6). After slaughter, carcasses were stored at $-4{ }^{\circ} \mathrm{C}$ for $6 \mathrm{~h}$ before dissection. Carcass-weight was measured after removing the feathers, feet, head, lungs, liver, kidneys, and gastrointestinal tract. Whole eviscerated carcasses were ground as frozen, homogenized and then returned to $-20{ }^{\circ} \mathrm{C}$ until composition analysis. Carcass water, protein, fat and ash contents were measured by nearinfrared reflectance spectroscopy (NIRS). Carcass chemical composition was measured in a $250 \mathrm{~g}$ sample (ground and homogenized) using a cell type Coarse in an NIR System 6500 (Silver Spring, MD, USA). Calibration curves for NIRS measurements were establisheded based on chemical analyses of 100 carcasses from various crosses and lines, as described by Klein et al. (2003). Dry matter, protein, fat and ash contents were determined in compliance with the standards of the Association of Official Analytical Chemists (AOAC, 1995). Klein et al. (2003), on comparing laboratory results and NIRS estimates from 19 carcasses, obtained coefficients of $0.88,0.96$ and 0.95 for protein, fat and water, respectively. Carcass fat (ether extract), protein, ash content and moisture were estimated as percentages of sample-weight (250 g of ground and homogenized carcass). Thus, carcass fat content (in grams) was obtained by multiplying the percentage of fat in the sample by BW6. To avoid a possible undesirable effect of carcass water content, the fat, protein and ash contents were also expressed as dry matter $(\%)$, by dividing sample fat content by carcass drymatter content $(\%)$ and multiplying by 100 . These traits were reported as protein percentage of wet carcass (PPWC), fat percentage of wet carcass (FPWC), ash percentage of wet carcass (APWC), protein percentage of dry matter (PPDM), fat percentage of dry matter (FPDM), and ash percentage of dry matter (APDM).

\section{Statistical analysis}

The normality of the residuals was verified for each trait, and records for which the standardized residual was higher than 3.5 or lower than -3.5 standard deviations were excluded. Least-squares analysis using the GLM procedure of SAS (SAS 9.1, SAS Institute, Cary, NC, USA) was used to define the fixed effects to be included in the mixed model. Animals of the same sex, hatch and genetic group (F2 TCTC and F2 CTCT) were considered, when contemplating fixed effects in the contemporary group (CG). These were found to be significant $(\mathrm{p}<0.05)$ for all traits.

The variance-covariance estimates and genetic parameters were obtained by the restricted-maximum- 
likelihood method, using an animal model and MTDFREML software (Boldman et al., 1995). The singleand two-trait animal models included the CG fixed-effect and random additive genetic and residual effects. The total number of animals in the numerator relationship matrix, including base animals, was 4,237.

\section{Results}

Descriptive statistics for traits evaluated in the 3,422 F2 individuals in this study are listed in Table 1. Single-trait heritability estimates, as well as genetic and phenotypic correlations between the traits studied, are presented in Table 2 . Heritability estimates obtained from two-trait analysis (results not shown) were very similar to those of single-trait analysis. For all the traits, excepting CY, PPWC and APWC, everything indicated the large proportion of phenotypic variance as being attributable to additive genetic effects.
The genetic association between BW6 and MP (Table 2) indicated that selection for higher live-weight would favor individuals with lower water accumulation in the carcass. In the case of BW6, and both protein and ash, results were moderate and inversely proportional, whereas the genetic association between BW6 and fat, although also moderate, directly proportional, regardless of whether measurements were of the percentage of wet carcass weight or dry matter.

A moderate genetic correlation was observed between CY and PPWC (Table 2), but not between CY and MP, FPWC, FPDM, PPDM, APWC or APDM. Thus, the genetic association of $\mathrm{CY}$ with others carcass components traits is expected to be low.

The genetic association between MP and PPWC and between MP and PPDM was high and directly proportional (Table 2). The same result was observed for ash content, with high and positive genetic correlation estimates be-

Table 1 - Mean, standard deviation (SD), coefficient of variation (CV) and minimum and maximum values for performance, carcass and body composition traits.

\begin{tabular}{lccccc}
\hline Trait $^{1}$ & Mean & SD & CV (\%) & Minimum & Maximum \\
\hline BW6 (kg) & 1.0 & 0.2 & 17.8 & 0.4 & 1.7 \\
CY (\%) & 64.9 & 2.2 & 3.4 & 49.0 & 81.6 \\
MP (\%) & 62.8 & 2.6 & 4.1 & 50.1 & 71.8 \\
PPWC (\%) & 18.8 & 0.9 & 17.7 & 7.3 & 24.3 \\
FPWC (\%) & 15.0 & 2.6 & 12.1 & 7.5 & 27.2 \\
APWC (\%) & 2.7 & 0.3 & 6.2 & 40.3 & 6.6 \\
PPDM (\%) & 50.7 & 3.1 & 12.1 & 24.5 & 3.9 \\
FPDM (\%) & 40.0 & 4.8 & 14.0 & 3.9 & 56.9 \\
APDM (\%) & 7.4 & 1.0 & & 11.2 \\
\hline
\end{tabular}

${ }^{1} \mathrm{BW} 6=$ body weight at 6 weeks of age; $\mathrm{CY}=$ carcass yield; $\mathrm{MP}=$ moisture percentage in the carcass; $\mathrm{PPWC}=$ protein percentage in wet carcass; FPWC $=$ fat percentage in wet carcass; $\mathrm{APWC}=$ ash percentage in wet carcass; $\mathrm{PPDM}=$ protein percentage in dry matter; FPDM $=$ fat percentage in dry matter; APDM = ash percentage in dry matter.

Table 2 - Heritability estimates (diagonal), genetic correlations (above the diagonal) and phenotypic correlations (below the diagonal) and their approximate standard errors (in parentheses) obtained for different carcass traits.

\begin{tabular}{lccccccccc}
\hline Trait $^{1}$ & BW6 (kg) & CY (\%) & MP (\%) & PPDM (\%) & FPDM (\%) & APDM (\%) & PPWC (\%) & FPWC (\%) & APWC (\%) \\
\hline BW6 (kg) & $0.31(0.07)$ & $0.22(0.18)$ & $-0.47(0.15)$ & $-0.45(0.15)$ & $0.46(0.14)$ & $-0.46(0.15)$ & $-0.34(0.28)$ & $0.45(0.14)$ & $-0.42(0.17)$ \\
CY (\%) & $0.33(0.02)$ & $0.20(0.05)$ & $-0.09(0.19)$ & $-0.03(0.19)$ & $0.03(0.19)$ & $-0.10(0.19)$ & $0.55(0.25)$ & $0.04(0.19)$ & $-0.09(0.20)$ \\
MP (\%) & $-0.33(0.02)$ & $-0.11(0.02)$ & $0.33(0.07)$ & $1.00(0.004)$ & $-0.99(0.01)$ & $0.97(0.02)$ & $0.83(0.20)$ & $-0.99(0.004)$ & $0.90(0.06)$ \\
PPDM (\%) & $-0.37(0.02)$ & $-0.13(0.02)$ & $0.79(0.01)$ & $0.48(0.09)$ & $-0.99(0.004)$ & $0.96(0.02)$ & $0.87(0.15)$ & $-1.00(0.003)$ & $0.87(0.06)$ \\
FPDM (\%) & $0.38(0.07)$ & $0.12(0.02)$ & $-0.73(0.01)$ & $-0.91(0.01)$ & $0.55(0.10)$ & $-0.97(0.01)$ & $-0.86(0.15)$ & $1.00(0.001)$ & $-0.91(0.04)$ \\
APDM (\%) & $-0.33(0.02)$ & $-0.16(0.02)$ & $0.52(0.02)$ & $0.65(0.01)$ & $-0.78(0.01)$ & $0.36(0.08)$ & $0.73(0.21)$ & $-0.98(0.01)$ & $0.98(0.01)$ \\
PPWC (\%) & $0.01(0.02)$ & $-0.002(0.02)$ & $-0.40(0.02)$ & $0.23(0.02)$ & $-0.20(0.02)$ & $0.14(0.02)$ & $0.02(0.01)$ & $-0.86(0.16)$ & $0.59(0.24)$ \\
FPWC (\%) & $0.38(0.02)$ & $0.12(0.02)$ & $-0.88(0.01)$ & $-0.92(0.01)$ & $0.96(0.005)$ & $-0.74(0.01)$ & $0.00(0.02)$ & $0.53(0.10)$ & $-0.91(0.05)$ \\
APWC (\%) & $-0.18(0.02)$ & $-0.12(0.02)$ & $0.04(0.01)$ & $0.30(0.02)$ & $-0.49(0.02)$ & $0.88(0.01)$ & $0.39(0.02)$ & $-0.37(0.02)$ & $0.15(0.04)$ \\
\hline
\end{tabular}

${ }^{1} \mathrm{BW} 6=$ body weight at 6 weeks of age; $\mathrm{CY}=$ carcass yield; $\mathrm{MP}=$ moisture percentage in the carcass; PPDM = protein percentage in dry matter; $\mathrm{FPDM}$ = fat percentage in dry matter; APDM = ash percentage in dry matter; $\mathrm{PPWC}=$ protein percentage in wet carcass; $\mathrm{FPWC}=$ fat percentage in wet carcass; APWC $=$ ash percentage in wet carcass. 
tween MP and APWC and between MP and APDM. In contrast, the genetic correlation estimates between MP and FPWC and between MP and FPDM were high and inversely proportional.

Genetic correlations between PPWC and PPDM, APWC and APDM, and FPWC and FPDM were high (Table 2), thereby indicating that measurements reported as the percentage of both dry matter and wet carcass weight, could be useful for evaluating the percentage of each trait in the carcass. However, when the breeding values for each trait, expressed as dry matter and wet weight, were plotted (Figure $1 \mathrm{a}, 1 \mathrm{~b}$ and $1 \mathrm{c}$ for protein, fat and ash, respectively), a firm association was only observed between APWC and APDM (Figure 1b) and between FPWC and FPDM (Figure 1c).

The genetic association between protein with ash content was high and directly proportional, whereas the genetic correlation between protein with fat, and ash with fat were high but inversely proportional (Table 2). Selection for higher carcass protein content would favor individuals with lower fat content and higher ash content.

As observed for genetic correlations, the estimates of phenotypic correlations between PPDM and FPDM, as well as between FPDM and APDM were high in magnitude and negative in signsign. Nevertheless, a high and positive phenotypic association was observed between PPDM and APDM.

Environmental correlation estimates were only important for MP and PPWC $(-0.59 \pm 0.04)$ and MP and APWC $(-0.23 \pm 0.05)$. These were similar in magnitude but opposite in signs to the genetic correlations observed between the same traits, this inverse response thereby indicating that inherent environmental associations should be taken into account during analysis.

\section{Discussion}

The lower mean body-weight at 6 weeks (Table 1) was expected, when compared to the results reported for pure broiler lines, with means ranging from 1.7 to $2.3 \mathrm{~kg}$ (Schmidt et al., 2003), and for chickens from a cross between a high-reproductive female line and a high-growth male line, as reported by Zerehdaran et al., (2004), who studied live weights at 49 days of age (mean of $2 \pm 0.3 \mathrm{~kg}$ ).

Although the mean for BW6 was low (Table 1), we emphasize that this is a broiler-layer cross developed for QTL mapping. Despite the possible inflation of genetic parameters for the traits studied (Table 2), through the use of such divergent lines, the aim was to estimate parameters for describing genetic associations between performance and carcass composition traits, as a means for understanding their genetic architecture, and not for selection. Furthermore, only few heritability estimates for these traits are reported in the literature.
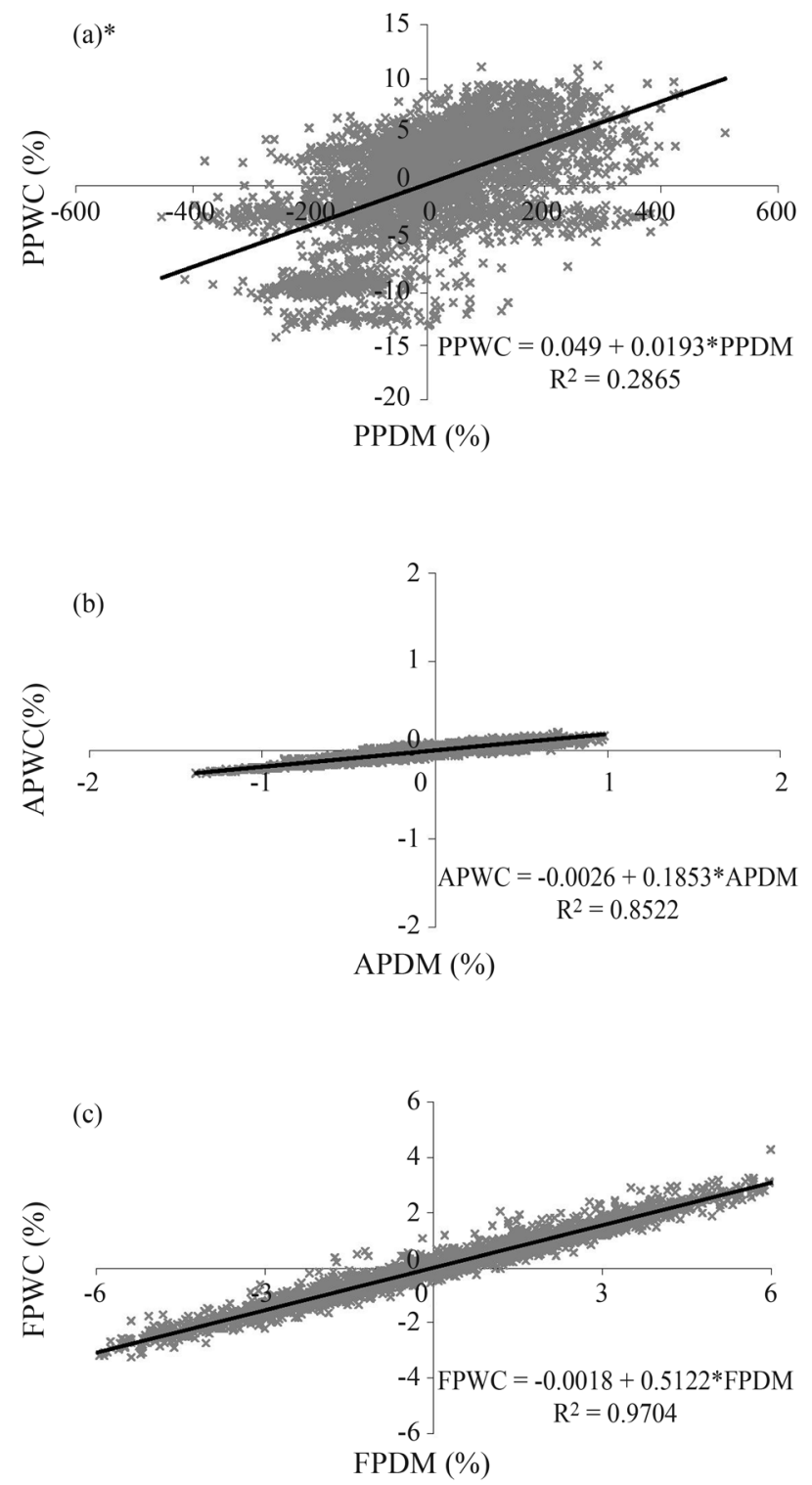

Figure 1 - Variation in breeding values for protein (a), ash (b) and fat content (c), expressed on a dry matter (PPDM, APDM and FPDM) and wet weight (PPWC, APWC and FPWC) basis. *PPDM and PPWC were multiplied by 100 .

The observed CY mean (Table 1) was similar to those reported by Schmidt et al. (2003) and Zerehdaran et al. (2004), which were $69.9 \%$ and $66.1 \%$, respectively. In this study, means for MP, PPWC, FPWC and APWC were similar to those observed by Washburn et al. (1975) and Pesti and Bakalli (1997), ranging from 63.9 to $67.1 \%$ for MP, $18.1 \pm 0.5 \%$ for PPWC, $11.7 \%$ for FPWC, and from $2.5 \pm 0.6 \%$ to $3.3 \pm 0.1 \%$ for APWC. Means for PPDM, FPDM and APDM were close to those obtained by Chambers and Fortin (1984), which were $50.4 \pm 0.7 \%$, $41.4 \pm 0.7 \%$ and $7.4 \pm 0.2 \%$, respectively. Perreault and Leeson (1992) obtained a higher mean ether extract percentage of $47.7 \pm 0.7 \%$ measured on a dry matter basis, at 43 days of age, when compared to our result for FPDM. 
The findings herein compiled, when compared with the literature, indicated that the use of a light-weight layer line, in the reciprocal cross under study, in no way affected carcass yield, or carcass protein, fat, moisture and ash contents, expressed as percentages of wet carcass weight and dry matter. The general concordance of our results with those of others adds to their credibility.

Genetic correlations between BW6 and CY (Table 2) were low. Zerehdaran et al. (2004) reported a similar genetic correlation estimate between live weight at 7 weeks of age and CY. Siegel (1984) and Becker et al. (1984) reported a genetic association between live weight and carcass ether extract, similar in magnitude to that encountered herein between BW6 and carcass fat content.

Carcass composition (protein, fat and ash content) expressed on a dry matter basis would be more appropriate for studying selection based on heritability estimates than the same traits measured as the percentage of wet carcass weight, since higher heritability estimates were obtained when carcass composition traits were expressed as percentage of dry matter. Carcass composition on a dry matter basis is more precise, through not being influenced by the sample, whereas measurements expressed as wet carcass weight might be influenced by the amount of water. However, besides having been used to predict carcass fatness (Taylor and Shaffner, 1975; Verstrate et al., 1980), percentages of carcass moisture may also be an effective means of accurately predicting percentages of carcass fat and protein content (Chambers and Fortin, 1984).

Similar heritability estimates, when compared to ours, were found by Le Bihan-Duval et al. (1999) (BW6 $0.42 \pm 0.02$ ) and Zerehdaran et al. (2004), (live-weight $0.33 \pm 0.07$ and $C Y$ at 7 weeks $0.41 \pm 0.07$ ). No heritability estimates were found in the literature for comparison with PPWC, PPDM, FPDM, FPWC, APDM and APWC data obtained herein.

Based on the heritability estimates found, in chickens, selection by the reduced amount of total fat (measured as the percentage of carcass dry matter or wet-carcass weight) would expectedly be effective in terms of genetic gain. Furthermore, the small magnitude of the standard errors of the heritability estimates is an indication of their reliability.

Selection for increased BW6 should result in a higher percentage of fat content and a lower one of protein and ash in the carcass. However, selection for CY would have little influence on carcass composition. The genetic correlations observed between the carcass-composition traits studied herein, indicate that selection by proteins may conduce to a higher percent of ash content and lower one of carcass-fat accumulation.

The moderate phenotypic correlation (Table 2) between BW6 and CY indicated that higher live-weights would not necessarily lead to higher CYs (Abram and Goodwin, 1977). Zerehdaran et al. (2004) reported phenotypic correlation estimates between live weight at 7 weeks of age and CY of $0.22 \pm 0.03$, whereas Ávila et al. (1993), when studying 50-day-old chickens, found a phenotypic correlation of 0.35 between BW6 and CY, similar to that observed herein.

The phenotypic association between BW6 and MP (Table 2) indicated the possibility of a higher live-weight resulting in lower water accumulation in the carcass. Pesti and Bakalli (1997) reported the relationship between these traits to be -0.22 .

An increase in BW6 will necessarily result in a higher percentage of fat content, and lower protein and ash contents in the carcass. With the exception of PPWC, the phenotypic associations between BW6 and carcass composition traits, here expressed as the percentage of wet carcass weight, were, in both direction and magnitude, similar to those reported by Chambers and Fortin (1984), who encountered phenotypic correlations between live weight (at 47 to 61 days of age) and PPWC, FPWC and APWC, of $-0.18,0.56$ and -0.25 , respectively. Siegel (1984) and Becker et al. (1984) reported a phenotypic association between live weight and ether extract in the carcass whose magnitude was similar to that found in the present study, between BW6 and fat content in the carcass. Furthermore, these correlations, as observed between BW6 and PPDM, FPDM and APDM were also similar to those noted by Chambers and Fortin (1984) between live weight and PPDM, FPDM and APDM of $-0.47,0.53$ and -0.46 , respectively.

Based on wet and dry matter, a negative phenotypic correlation between moisture and carcass lipid percent was estimated herein, as occurred with Silva et al. (2003) who obtained a highly negative estimate $(\mathrm{r}=-0.88 ; \mathrm{p}<0.0001)$ between the same two factors. Although the correlation between MP and PPWC was negative, this was high and positive between MP and PPDM and MP and APDM, although very low between MP and APWC. Chambers and Fortin (1984) reported phenotypic associations of 0.92 (protein and moisture) and 0.72 (ash and moisture), thus in agreement with the present results.

Chambers and Fortin (1984) reported phenotypic associations of -0.95 between protein and fat, -0.80 between fat and ash, and 0.74 between protein and ash, in carcass dry matter, thus in agreement with the present results. Although no linear relationship was observed between PPWC and FPWC, Washburn et al. (1975) and Chambers and Fortin (1984) obtained estimates of -0.46 and -0.70 , respectively.

Although a positive phenotypic correlation was established between APWC and PPWC (Table 2), this was negative between APWC and FPWC. Similar results were reported by Chambers and Fortin (1984) with 0.42 between the former and -0.46 between the latter. In the present study, positive relationships were observed between FPWC and FPDM, PPWC and PPDM, and APWC and APDM, 
thus indicating a directly proportional linear association between these traits.

\section{Acknowledgments}

Financial support was provided by Embrapa (Empresa Brasileira de Pesquisa Agropecuária). B.N. Nunes and R.P. Savegnago were granted scholarships from CAPES (Coordenação de Aperfeiçoamento de Pessoal de Nível Superior/Programa de Pós-Graduação em Genética e Melhoramento Animal - FCAV/ UNESP), and S.B. Ramos and K. Nones received scholarships from FAPESP (Fundação de Amparo à Pesquisa do Estado de São Paulo).

\section{References}

Abram JL and Goodwin TL (1977) A study of broiler carcass yields from five commercial strains. Poult Sci 56:16911692.

AOAC (1995) Official Methods of Analysis. 16th edition. Association of Official Analytical Chemists, Arlington, 1141 pp.

Ávila VS, Ledur MC, Barioni Jr W, Schmidt GS and Costa CN (1993) Desempenho e qualidade de carcaça em linhagens comerciais de frangos de corte. Pesqui Agropecu Bras 28:649-656 (Abstract in English).

Becker WA, Spencer JV, Mirosh LW and Verstrate JA (1984) Genetic variation of abdominal fat, body weight and carcass weight in a female broiler line. Poult Sci 63:607-611.

Boldman KG, Kriese LA, Van Vleck LD, Van Tassel CP and Kachman SD (1995) A Manual for the Use of MTDFREML. A Set of Programs to Obtain Estimates of Variance and Covariances (Draft). USDA-ARS, Lincoln, $120 \mathrm{pp}$.

Burt DW (2002) Applications of biotechnology in the poultry industry. Worlds Poult Sci J 58:5-13.

Chambers JR and Fortin A (1984) Live body and carcass measurements as predictors of chemical composition of carcasses of male broiler chickens. Poult Sci 63:2187-2196.

Chambers JR (1995) Advantages and disadvantages of genetic improvement of meat-type poultry and possible solutions. Proc Simpósio Técnico de Matrizes de Corte, Chapecó, v. 1, pp. 120-131.

Havenstein GB, Toelle VD, Nestor KE and Bacon WL (1988) Estimates of genetic parameters in turkeys. 2. Body weight and carcass characteristics. Poult Sci 67:1388-1399.

Ikeobi CO, Woolliams JA, Morrice DR, Law A, Winsor D, Burt DW and Hocking PM (2002) Quantitative trait loci affecting fatness in the chicken. Anim Genet 33:428-435.

Klein CH, Lima GMM, Ledur MC and Suzin L (2003) Espectroscopia infravermelho próxima para predição da composição de carcaça de frangos de corte. Rev Bras Cienc Avic (Supl) 5:108 (Abstract in English).

Lagarrigue S, Pitel F, Carré W, Absht B, Le Roy P, Neau A, Amigues Y, Sourdioux M, Simon J, Cogburn NL, et al. (2006) Mapping quantitative trait loci affecting fatness and breast muscle weight in meat-type chicken lines divergently selected on abdominal fatness. Genet Sel Evol 38:85-97.
Le Bihan-Duval E, Millet N and Remignon H (1999) Broiler meat quality: Effect of selection for increased carcass quality and estimates of genetic parameters. Poult Sci 78:822-826.

Leenstra FR, Vereijken PFG and Pit R (1986) Fat deposition in a broiler sire strain I. Phenotypic and genetic variation in and correlations between abdominal fat, body weight and feed conversion. Poult Sci 65:1225-1235.

Lin CY (1981) Relationship between increased body weight and fat deposition in broilers. Worlds Poult Sci J 37:106-110.

Nadaf J, Gilbert H, Pitel F, Berri CM, Feve K, Beaumont C, Duclos MJ, Vignal A, Porter TE, Simon J, et al. (2007) Identification of QTL controlling meat quality traits in an F2 cross between two chicken lines selected for either low or high growth rate. BMC Genomics 8:e155.

Nones K, Ledur MC, Ruy DC, Baron EE, Moura ASAMT and Coutinho LL (2005) Genetic linkage map of chicken chromosome 1 from a Brazilian resource population. Sci Agric 62:12-17.

Perreault N and Leeson S (1992) Effect of environmental temperature, dietary energy, and feeding level on growth carcass composition of male broiler chickens to 35 days of age. Can J Anim Sci 72:695-702.

Pesti GM and Bakalli RI (1997) Estimation of the composition of broiler carcasses from their specific gravity. Poult Sci 76:948-951

Schmidt GS, Coutinho LL, Figueiredo EAP, Ledur MC and Alves HJ (2003) Morphological genetic markers for selection of broiler lines. Rev Bras Cienc Avic 5:175-178.

Siegel PB (1984) Factors influencing excessive fat deposition in meat poultry. 1. Genetics. Proc 17th World's Poultry Congress, Helsinki, pp. 51-52.

Silva JHV, Albino LFT and Nascimento AH (2003) Estimativas da composição anatômica da carcaça de frangos de corte com base no nível de proteína da ração e peso da carcaça. $\mathrm{R}$ Bras Zootec 32:344-352 (Abstract in English).

Taylor MH and Shaffner CS (1975) The relationship of ether extract and moisture in eviscerated broilers. Poult Sci 54:663666.

Tercic D, Holcman A, Dovc P, Morrice DR, Burt DW, Hocking PM and Horvat S (2009) Identification of chromosomal regions associated with growth and carcass traits in an F3 full sib intercross line originating from a cross of chicken lines divergently selected on body weight. Anim Genet 40:743748.

Verstrate JA, Spencer JV, Mirosh LW and Becker WA (1980) A comparison of methods for determining the fat content of broiler carcasses. Poult Sci 59:298-302.

Washburn KW, Guill RA and Edwards Jr HM (1975) Influence of genetic differences in feed efficiency on carcass composition of young chickens. J Nutr 105:1311-1317.

Zerehdaran S, Vereijen ALJ, Van Arendonk JAM and Van Der Waaij EH (2004) Estimation of genetic parameters for fat deposition and carcass traits in broilers. Poult Sci 83:521525 .

\section{Associate Editor: Alexandre Rodrigues Caetano}

License information: This is an open-access article distributed under the terms of the Creative Commons Attribution License, which permits unrestricted use, distribution, and reproduction in any medium, provided the original work is properly cited. 